\title{
Comparison of Semen Characteristics of Good and Poor Freezable Jersey Crossbred Bulls
}

\author{
P. Perumal ${ }^{1 *}$, A. K. Barik², D. N. Mohanty², S. Das², P. C. Mishra² and S. Chang ${ }^{1}$ \\ ${ }^{1}$ ICAR-National Research Center on Mithun, Medziphema, Nagaland (797 106), India \\ ${ }^{2}$ Odisha University of Agriculture and Technology, Bhubaneswar, Odisha (751 003), India
}

\section{Article History}

Manuscript No. AR1459

Received in $9^{\text {th }}$ September, 2015

Received in revised form $10^{\text {th }}$ August, 2016

Accepted in final form $30^{\text {th }}$ August, 2016

\section{Correspondence to}

${ }^{*} E$-mail: perumalponraj@gmail.com

\section{Keywords}

Good and poor freezer, seminal characters, crossbred bulls

\begin{abstract}
A study was conducted to assess the semen quality parameters in good and poor freezable Jersey crossbred bulls. The experimental bulls were 4-6 years of age with good body condition (score 5-6) selected and were maintained under optimum nutrition and managemental practices as per the standard criteria fixed for maintenance of breeding bulls in bull stations. In this study, six bull were selected and were divided into $\operatorname{good}(n=3)$ and poor $(n=3)$ freezable bulls based on seminal characters of the post thaw semen. The bulls have been classified into good and poor freezable depending upon the criteria of producing semen with $\geq 50 \%$ (good freezability) and $<50 \%$ (poor freezability) post-thaw sperm motility. Good freezable semen could withstand satisfactorily the deep freezing temperature while the poor freezable semen could not do so and lost some of their seminal characteristics after thawing. The semen was collected by AV method and a total of 36 ejaculates, 6 ejaculates from each bull were collected for assessment. The following seminal parameters were taken for the experimental study namely volume $(\mathrm{ml})$, mass activity (grade), individual motility (per cent), sperm concentration $\left(\mathrm{X} 10^{6} \mathrm{ml}^{-1}\right)$, live sperm (per cent), total sperm abnormality (per cent), loss of acrosomal integrity (per cent) and plasma membrane integrity by hypo-osmotic swelling test (HOST; per cent). The result revealed that there was a highly significant difference $(p<0.01)$ prevailed in sperm concentration while significant difference $(p<0.05)$ was observed in the other seminal parameters between good and poor freezable bull semen.
\end{abstract}

\section{Introduction}

The bull producing semen, which contains sperm provide about $50 \%$ of genetic materials to the offspring. The bull is producing voluminous semen and several hundreds of millions of sperm in natural service. While only a few millions of sperm are actually required to reach the site of fertilization for a successful conception, the majority of the remaining sperm are wasted. To overcome this wastage and proper utilization of this semen, the freezing of semen, thawing and insemination process was adopted. The bulls are classified into good and poor freezable depending upon the criteria of producing semen with $\geq 50 \%$ (good freezability) and $<50 \%$ (poor freezability) post-thaw sperm motility. Good freezable semen could withstand satisfactorily the deep freezing temperature while the poor freezable semen could not do so and lost some of their seminal characteristics after thawing. In a recent study it has been possible to assign individual boars into good, average and poor freezer groups on the basis of their post-thaw sperm viability using a system of multivariate pattern analysis
(Thurston et al., 1999). The sperm membrane is made up of phospholipid-bi-layer and is responsible for maintaining the membrane integrity. Any defect in this membrane makes the sperm unable to withstand the freezing temperature which can further aggravate the membrane integrity and leads to poor motility, fertilization and conception rate. Poor freezability leads to affect sperm membrane integrity and nuclear integrity which in turn reduces the motility of sperm and increases the sperm abnormality and dead sperm percentage. This ultimately reduces the fertilization and conception rate. The freezability is dependent on many factors like genetic factors, nutritional status, availability of antioxidants (Perumal et al., 2011a; Perumal et al., 2011b; Perumal et al., 2012a; Perumal et al., 2012b), feeding of antioxidants (Jayaganthan et al., 2013) presence of free radicals, environment conditions, disease conditions of various systems and reproductive organs, etc. The bulls used in semen stations are regarded as good or poor freezable, based on previous record of post thaw analysis of seminal parameters and assay of enzyme estimation like lipid peroxidase and SGPT (Perumal et al., 2013). 


\section{Materials and Methods}

This work was conducted in Department of Animal Reproduction, Gynaecology and Obstetrics, Odisha Veterinary College in collaboration with frozen semen bank (FSB), Cuttack under State Department of Animal Husbandry and Veterinary Services, Government of Odisha. The experimental bulls were 4 to 6 years of age with good body condition (score 5-6) selected and maintained under optimum nutrition and manage mental practices as per the standard criteria fixed for maintenance of breeding bulls in bull stations. In this study, six bull $(n=6)$ were selected and were divided into $\operatorname{good}(n=3)$ and poor $(\mathrm{n}=3)$ freezable bulls based on seminal characters of the post thaw semen. Good freezable semen could withstand the freezing temperature while poor freezable semen could not and lost their seminal characters after thawing. The bulls were classified into good and poor freezable depending upon the criteria of producing semen with $\geq 50 \%$ (good freezability) and $<50 \%$ (poor freezability) post-thaw sperm motility. The semen was collected by AV method after sexual stimulation by one false mount and 5-10 min restraint and a total of 36 ejaculates (6 ejaculates from each bull) were collected for assessment. Immediately after collection, the semen collecting tubes were taken to the laboratory and placed in water bath at $34^{\circ} \mathrm{C}$. The following semen characteristics were considered for the experimental study namely colour, volume, mass motility, individual motility of spermatozoa, sperm concentration, live sperm percentage, total sperm abnormality, loss of acrosomal integrity and hypo osmotic swelling positive sperm and were recorded using standard procedures. Mass motility was graded on a 5-point scale basis ranging from $0-5$. Each ejaculate was evaluated for mass motility and individual motility of spermatozoa using phase contrast microscope. Smear of each semen sample was made taking one drop of semen and 4-5 drops of Eosin-Nigrosin stain. Each smear was counted for the percentage of eosin stained dead spermatozoa by examining at least 100 sperms in $100 \times$ of phase contrast microscope. Few drops of each semen sample were fixed in about 2-3 ml of formalized buffer saline solution and then examined under $40 \times$ to count the percentage of abnormal sperm cells (Sattar and Mirza, 2002). The average values (Mean \pm SE) for each trait in the two groups were evaluated and compared by using paired t-test (Snedecor and Cochran, 1980).

\section{Results and Discussion}

The story of semen cryopreservation has been one of apparent early success followed by decades of marginal improvement. However, it is becoming increasingly clear that, even when membrane-intact, motile spermatozoa are recovered after thawing, these cells are functionally very different from fresh spermatozoa. If frozen-thawed semen is to be used in the same way as fresh semen, and be able to achieve high fertility rates from intrauterine or even intra-vaginal insemination, without very careful monitoring of the female cycle, it will be necessary to substantially improve techniques for freezingthawing. A greater understanding of the causes of cryo-injury and the effects of temperature, osmotic and oxidative stresses on sperm membranes are required in order to preserve the natural heterogeneity of a semen sample and to limit pseudomaturational changes in the cells. Irrespective of the freezing protocol employed, variations have been observed between males regarding freezability and fertility of semen, so they could be classified as good freezers or bad freezers (Leboeuf et al., 2000; Perumal et al., 2012a; Perumal et al., 2012b).

The different seminal parameters were presented in form of a Table 1 . The values in table revealed that there is a significant difference $(p<0.05)$ found in the sperm parameters except in sperm concentration. However a highly significance difference $(p<0.01)$ prevailed in sperm concentration between good and poor freezable bull semen. Even when semen does freeze well, frozen/thawed sperm have a shorter survival time in cow's uterus after insemination and may be less fertile than if the semen had been inseminated fresh (either by AI or by natural mating) or after chilling and short-term storage. So the survivability of sperm after insemination is important for better conception rate. The ovum has capacity to repair and

Table 1: Comparison of semen characteristics of good and poor freezable Jersey crossbred bulls

\begin{tabular}{|c|c|c|c|}
\hline $\begin{array}{l}\text { Sl. } \\
\text { No. }\end{array}$ & Seminal characters & $\begin{array}{c}\text { Good freezer } \\
(\mathrm{n}=3)\end{array}$ & $\begin{array}{c}\text { Poor freezer } \\
(\mathrm{n}=3)\end{array}$ \\
\hline 1. & No. of ejaculates & 36 & 36 \\
\hline 2. & Volume (ml) & $6.40 \pm 0.41^{\mathrm{a}}$ & $5.20 \pm 0.36^{\mathrm{b}}$ \\
\hline 3. & $\begin{array}{l}\text { Mass activity } \\
\text { (grade; } 0 \text { to } 5 \text { ) }\end{array}$ & $2.50 \pm 0.13$ & $2.40 \pm 0.13$ \\
\hline 4. & $\begin{array}{l}\text { Individual motility } \\
(\%)\end{array}$ & $77.13 \pm 0.60$ & $75.33 \pm 0.77$ \\
\hline 5. & $\begin{array}{l}\text { Sperm concentra- } \\
\text { tion }\left(\times 10^{6} \mathrm{ml}^{-1}\right)\end{array}$ & $1240.26 \pm 82.77^{a^{* *}}$ & $\begin{array}{c}1007.53 \\
\pm 50.28^{b * *}\end{array}$ \\
\hline 6. & Live sperm $(\%)$ & $89.95 \pm 0.49^{a}$ & $85.22 \pm 0.28^{\mathrm{b}}$ \\
\hline 7. & $\begin{array}{l}\text { Total sperm } \\
\text { abnormality (\%) }\end{array}$ & $6.33 \pm 0.19^{\mathrm{a}}$ & $9.39 \pm 0.27^{b}$ \\
\hline 8. & $\begin{array}{l}\text { Loss of acrosomal } \\
\text { integrity }(\%)\end{array}$ & $6.46 \pm 0.9^{\mathrm{a}}$ & $12.73 \pm 1.12^{\mathrm{b}}$ \\
\hline 9. & $\begin{array}{l}\text { Hypo osmotic } \\
\text { swelling positive } \\
\text { sperm (\%) }\end{array}$ & $85.78 \pm 0.42^{\mathrm{a}}$ & $80.38 \pm 0.32^{b}$ \\
\hline
\end{tabular}


to maintain the integrity of nucleus of sperm for successful fertilization up to $8 \%$ of damage and beyond that the zygote will be dead prematurely. So the integrity of sperm nucleus and sperm membrane is essential for higher pregnancy rate. These two parameters are affected by deep freezing in ultra low temperature and the thawing process.

The mechanisms underlying differences in cryosensitivity between different individuals are yet to be elucidated. But there is some evidence for physiological differences between spermatozoa from individuals of the same species. Harrison et al. (1996) reported that the stimulatory effects of bicarbonate on the process of capacitation differ among individual boars. However, such differences could be genetic or non-genetic in origin. A role for a genetic component in the overall effect is suggested by the strain differences in cryosensitivity recorded for mice (Nakagata and Takeshima, 1993). The positive effects of selection would also seem to point to a genetic component for 'good freezing' as a characteristic. Individual differences have been recorded for bull semen and allowances have been made for so-called poor freezers by packaging straws with more spermatozoa or by adjusting freezing protocols for individual bulls (Parkinson and Whitfield, 1987). If there has been a significant problem with variation between individual bulls, it has been largely overcome by an ongoing selection process whereby, even though bulls have not been selected primarily on the basis of their fertility, those whose semen has proved to be subfertile, have been removed from freezing programmes. This variability is relatively independent of prior semen quality and the semen of certain individuals consistently freezes with less cryoinjury than that of others (Bhosrekar et al., 1994). The fact that males can often be classified as good freezers or bad freezers implies that certain characteristics of membrane structure, which may be genetically determined, predispose towards survival under cryopreservation stress (Watson, 2000). There are instances in which certain semen samples within a species having good pre-freeze motility, still results in poor freezability. Differences in either ejaculation frequency, or in epididymal transit times and sperm mixing in the epididymis, provide a potential mechanism for variability in responses to subsequent temperature explaining why ejaculates within individuals can vary in their responses to cryopreservation (Watson, 1995). Further, it is of interest to explore whether any adverse changes that take place during exposure to the cryoprotectant during equilibration, influence the freezability of spermatozoa (Amann et al., 1993).

\section{Conclusion}

Basing on the prefreeze and post thaw seminal characteristics, the bulls can be graded as good or poor freezable. The poor freezable bulls can suitably be used in Natural service or can be used in frozen semen artificial insemination, after minor corrective measures in processing.

\section{References}

Amann, R.P., Hammerstedt, R.H., Veeramachaneni, D.N.R., 1993. The epididymis and sperm maturation: a perspective. Reproduction, Fertility and Development $5,361-381$.

Bhosrekar, M.R., Mokashi, S.P., Purohit, J.R., Gokhale, S.B., Mangurkar, B.R., 1994. Morphological changes in cattle and buffalo sperm on glycerolation and deep freezing. Indian Veterinary Journal 71, 189-190.

Harrison, R.A.P., Ashworth, P.J.C., Miller, N.G.A., 1996. Bicarbonate $/ \mathrm{CO}_{2}$, an effector of capacitation, induces a rapid and reversible change in the lipid architecture of boar sperm plasma membranes. Molecular Reproduction and Development 45, 378-391.

Jayaganthan, P., Perumal, P., Balamurugan, T.C., Verma, R.P., Singh, L.P., Pattanaik, A.K., Kataria, M., 2012. Effects of Tinospora cordifolia supplementation on semen quality and hormonal profile of ram. Animal Reproduction Science 140(1), 47-53.

Leboeuf, B., Restall, B., Salamon, S., 2000. Production and storage of goat semen for artificial insemination. Animal Reproduction Science 62, 113-141.

Nakagata, T., Takeshima, T., 1993. Cryopreservation of mouse spermatozoa from inbred and $\mathrm{F}_{1}$-hybrid strains. Experimental Animals 42, 317-320.

Parkinson, T.J., Whitfield, C.H., 1987. Optimization of freezing conditions for bovine spermatozoa. Theriogenology 27 , 781-797.

Perumal, P., Selvaraju, S., Barik, A.K., Mohanty, D.N., Das, S., Mishra, P.C., 2011b. Role of reduced glutathione in improving post-thawed frozen seminal characters of poor freezable Jersey crossbred bull semen. Indian Journal of Animal Science 81(8), 807-810.

Perumal, P., Selvaraju, S., Selvakumar, S., Barik, A.K., Mohanty, D.N., Das, S., Das, R.K., Mishra, P.C., 2011 a. Effect of pre-freeze addition of cysteine hydrochloride and reduced glutathione in semen of crossbred jersey bulls on sperm parameters and conception rates. Reproduction in Domestic Animals 46(4), 636-641.

Perumal, P., Selvaraju, S., Barik, A.K., Mohanty, D.N., Das, S., Mishra, P.C., Veeraselvam, M., 2012a. Reduced glutathione and cysteine hydrochloride on sperm motility and velocity parameters of poor crossbred bull semen. International Journal of Bio-Resource and Stress Management 3(2), 145-151.

Perumal, P., Selvaraju, S., Barik, A.K., Mohanty, D.N., Das, S., Mishra, P.C., Veeraselvam, M., 2012b. Cysteine 
hydrochloride on post-thawed seminal characters of poor freezable Jersey crossbred bull semen. International Journal of Bio-Resource and Stress Management 3(2), 232-235.

Perumal, P., Vupru, K., Rajkhowa, C., 2013. Effect of addition of taurine on the liquid storage $\left(5^{\circ} \mathrm{C}\right)$ of mithun (Bos frontalis) semen. Veterinary Medicine International 2013, 7 pages, Article ID: 165348. http://dx.doi. org/10.1155/2013/165348.

Sattar, A., Mirza, R.H., 2002. Comparison of semen characteristics of reciprocal crossbred bulls of friesian $\times$ sahiwal origin. International Journal of Agriculture and Biology 4(4), 474-475.

Snedecor, G.W., Cochran, W.G., 1980. Statistical methods applied to experiments in agriculture and biology. $\left(7^{\text {th }}\right.$ Edn.). Iowa State University Press, Ames, Iowa.

Thurston, L.M., Watson, P.F., Holt, W.V., 1999. Sources of variation in the morphological characteristics of sperm subpopulations assessed objectively by a novel automated sperm morphology analysis system. Journal of Reproduction and Fertility 117, 271-280.

Watson, P.F., 2000. The causes of reduced fertility with cryopreserved semen. Animal Reproduction Science 60, 481-492.

Watson, P.F., 1995. Recent developments and concepts in the cryopreservation of spermatozoa and the assessment of their post-thawing functions. Reproduction, Fertility and Development 7, 871-891. 